\title{
Dampak Kepemimpinan, Kompensasi dan Motivasi Kerja Pada Kinerja
}

\author{
Yasir Arafat ${ }^{1}$, Ade Satria Margolang ${ }^{2}$, Agus Mulyani $^{3}$, Tri Darmawati ${ }^{4}$ \\ ${ }^{1}$ Manajemen, F. Ekonomi dan Bisnis UPGRI Palembang, yasirarafat@univpgri-palembang.ac.id \\ ${ }^{2}$ Manajemen, F. Ekonomi dan Bisnis UPGRI Palembang \\ ${ }^{3}$ Manajemen, F. Ekonomi dan Bisnis UPGRI Palembang, agusmulyani@univpgri-palembang.ac.id \\ ${ }^{4}$ Manajemen, F. Ekonomi dan Bisnis UPGRI Palembang, tridarmawati@univpgri-palembang.ac.id
}

\begin{abstract}
ABSTRAK
Analisis kepemimpinan, kompensasi dan motivasi kerja pada kinerja dilakukan pada pegawai salah satu perusahaan jasa transportasi di Kota Palembang. Penelitian dilakukan dengan cara metode kuantitatif yaitu mengambil data sampel pada populasi kemudian dianalisis menggunakan statistik sehingga dapat mendeskripsikan kaitan antar variabel. Sampel pada studi ini 40 orang pegawai pada salah satu perusahaan jasa transportasi di Kota Palembang. Analisis data menggunakan statistik inferensial. Hasil analisis diperoleh koefisien regresi kepemimpinanpositif 0,262 , nilai signifikan 0,011 kurang dari 0,05. thitung variabel kepemimpinan 2,696 > tabel 2,028. Hasil ini membuktikan kepemimpinanmemberi pengaruh positif, signifikanpada kinerja. Hasil studilainnya diperoleh koefisien regresi kompensasipositif 0,230 , signifikan 0,015 kurang dari 0,05 . thitung variabel kompensasi $2,549>$ ttabel 2,028. Studi ini membuktikan kompensasi memberi pengaruh secara positif,signifikan pada kinerja. Hasil studiberikutnya diperoleh koefisien regresi motivasi kerja positif 0,399 , signifikan 0,002 kurang dari 0,05 . thitung variabel motivasi kerja $3,281>$ tabel 2,028 . Studi ini membuktikan motivasi kerja memberi pengaruh secara positif,signifikan pada kinerja.
\end{abstract}

kata kunci : kepemimpinan, motivasi kerja,kompensasi dan kinerja

\section{ABSTRACT}

The analysis of leadership, compensation and work motivation on performance was carried out on employees of one of the transportation service companies in Palembang City. The research was conducted by means of quantitative methods, namely taking sample data on the population and then analyzed using statistics so as to describe the relationship between variables. The sample in this study is 40 employees at a transportation service company in Palembang City. Data analysis using inferential statistics. The results of the analysis obtained a positive leadership regression coefficient of 0.262 , a significant value of 0.011 less than 0.05 . $t$ count leadership variable 2,696> $t$ table 2,028. These results prove leadership has a positive, significant effect on performance. The results of other studies obtained a positive compensation regression coefficient of 0.230 , significant 0.015 less than 0.05. tcount of compensation variable 2,549> ttable 2,028. This study proves that compensation has a positive, significant effect on performance. The results of the following study obtained a positive work motivation regression coefficient of 0.399 , significant 0.002 less than 0.05 . $t$ count work motivation variable $3,281>t$ table 2,028. This study proves that work motivation has a positive, significant effect on performance.

keywords: leadership, work motivation, compensation and performance

\section{A. PENDAHULUAN}

Saat ini diyakini bahwa perusahaan jasa transportasi akan terus tumbuh setiap tahunnya. Hal ini seiring dengan perkembangan teknologi, masifnya pembangunan infrastruktur, ekspansi pabrik dalam jumlah besar dan mobilitas barang ataupun manusia itu sendiri. Untuk itu perusahaan harus mampu memberikan pelayanan, jasa dan kinerja maksimal yang berasal dari pegawainya. Semakin berkembang dan majunya teknologi dalam kehidupan membuat berbagai perubahan-perubahan yang harus 
disikapi dan ditindaklanjuti dengan berbagai inovasi. (Wibowo, 2014) menyatakan kinerja merupakan kegiatan yang dihasilkan pengelola sumber daya organisasi, sehingga kinerja menjadi sangat penting bagi organisasi mencapai tujuannya. Untuk itu kegiatan yang dikerjakan organisasi diupayakan untuk terus ditingkatkan. (Moeheriono, 2012) menjelaskan kinerja adalah gambaran mengenai pencapaian kerja progam-program berkaitan dengan perencanaan utama organisasi melalui strategi-strategi implementasi kegiatan yang sesuai dengan visi dan misi organisasi. (Hasibuan, 2014) mengatakan kinerja merupakan pencapaian yang dihasilkan seseorang saat melakukan pekerjaan yang ditugaskan pada yang bersangkutan dengan memperhatikan kemampuan, keahlian, rekam jejak, kesungguhan, dan waktu penyelesaian pekerjaan. Dari pendapat ahli tersebut dapat disintesiskan kinerja adalah kegiatan yang dilaksanakan pegawai untuk kemajuan perusahaan dengan menghasilkan suatu karya, baik berupa pelayanan, jasa untuk mencapai tujuan kerja organisasi.

$$
\text { Kinerja dipengaruhi banyak }
$$
faktor, antara lain kepemimpinan. Menurut (Sunyoto, 2012) kepemimpinan adalah upaya-upaya pemimpin untuk mempengaruhi sifat kelompok atau perorangan, dengan tujuan yang mungkin sama atau berbeda bagi pemimpin maupun orang-orang yang dipimpin atau dalam kelompok organisasi. (Wukir, 2013) menjelaskan kepemimpinan adalah kemampuan abstrak memotivasi dan mengajak sekelompok orang bertindak untuk suatu tujuan tertentu. Sedangkan (Ardana, Mujiati, \& Utama, 2012) menyatakan kepemimpinan adalah orang yang mampu memimpin, dengan kata lain mampu untuk mengajak orang lain melakukan pekerjaan yang ditugaskan. Kepemimpinan sangat penting dalam menjalankan roda organisasi atau perusahaan. Organisasi yang berhasil apabila dijalankan dengan kepemimpinan yang menyesuaikan keadaan dan perubahan zaman. Sehingga seorang pemimpin harus dapat menyesuaikan kepemimpinan dengan orang, kelompok dan kondisi lingkungan baik internal maupun eksternal dalam organisasi. Dari berbagai pendapat tentang pengertian kepemimpinan dapat dipahami bahwa kepemimpinan merupakan kapasitas seseorang untuk melakukan apa yang menjadi keiginannya dan mempunyai karakter yang baik untuk mengajak, mempengaruhi, dan membuat orang lain tertarik untuk mendengar, mematuhi apa yang diperintahkan dan melakukan apa yang di minta untuk dikerjakan sesuai harapan guna mencapai apa yang menjadi tujuan suatu kelompok maupun tujuan perorangan dalam melakukan pekerjaan yang mungkin sama atau berbeda tujuannya".

Faktor lain yang mempengaruhi kinerja antara lain kompensasi. (Suparyadi, 2015), mengatakan kompensasi adalah semua imbalan yang diterima karyawan atas jerih payah dan kontribusi yang diberikan pada perusahaan, berupa finansial atau non finansial. Menurut (Sastrohadiwiryo, 2013) Kompensasi merupakan suatu imbalan atau penghargaan dari perusahaan pada karyawan, karena karyawan telah menyumbangkan tenaga dan pikiran mereka untuk keberhasilan perusahaan sesuai dengan harapan dan keinginan yang ditetapkan perusahaan. (Hasibuan, 2014) menjelaskan kompensasi berupa pendapatan atau hasilyang didapat pegawai dalam bentuk uang, barang yang diterima langsung atau tidak 
langsung sebagai penghargaan untuk jasa yang diberikannya bagiorganisasi atau perusahaan. (Sinambela, 2018) Kompensasi yaitu keseluruhan dari semua hadiah, yang diberikan suatu perusahaan atau organisasi pada karyawannya sebagai imbalan karena jasa yang merekaberikan. Kompensasi menjadi hal yang paling pentingdalam pengembangan suatu organisasi maupun perusahaan. Kompensasi menjadi tujuan paling besar bagi karyawan untuk meningkatkan kualitas, mempertahankan dan mengabdikan dirinya. Perusahaan menginginkan selalu ada peningkatan kinerja yang dilakukan para pegawainya, untuk meningkatkan kinerja perlu pemberian kompensasi yang tepat, adil dan memuaskan. Banyak faktor yang menjadi pertimbangan pihak manajemen perusahaan dalam memberikan kompensasi. Antara lain masa kerja, pendidikan, beban kerja, target dan lain sebagainya. Dari beberapa defenisi tersebut dapat disintesiskan kompensasi adalah semua bentuk balas jasa, penghargaan dari perusahaan pada karyawan yang telah memberikan jerih payah dan kontribusi mewujudkan tujuan perusahaan.

Faktor lainnya yang juga mempengaruhi kinerja adalah motivasi kerja. (Hasibuan, 2014) motivasi kerja yaitu dorongan yang dapat membuat semangat kerja bangkit dan menjadikan seseorang dapat bekerja sama, secara efektif dan dapat berbaur dengan pekerjaan untuk mencapai nilai kepuasan. Menurut (Wibowo, 2014) menyatakan motivasi adalah keadaan yang menyebabkan intensitas, arah dan usaha secara konsisten untuk mencapai tujuan. Sedangkan (Suranta, 2002) menyatakan sesuatu yang timbul dari diri seseorang sebagai proses karena adanya dorongan dari luar dirinya yang dapat berpengaruh pada pekerjaan. Seseorang yang termotivasi dalam bekerja akan mendapatkan dorongan, semangat dalam menuntaskan beban pekerjaan yang menjadi tanggungjawabnya. Begitu juga sebaliknya seorang pegawai yang tidak mempunyai motivasi dalam bekerja akan kehilangan dorongan dan semangat dalam mengerjakan pekerjaan yang dibebankan kepadanya. Dari beberapa teori tersebut dapat disintesiskan motivasi kerja merupakan proses yang timbul padadiriseseorang atau berasal dari luar dirinya sendiri untuk melakukan kegiatan pada suatu organisasi. Hasil kinerja yang maksimal biasanya berasal dari motivasi dalam diri seseorang, jika hati dan pikirannya dalam keadaan tenang dan apa yang akan dikerjakannya sesuai hati nurani hasilnya akan baik, sebaliknya jika melakukan pekerjaan karena keterpaksaan yang tidak ada dorongan dari dalam dirinya kemungkinan hasilnya tidak akan maksimal.

\section{B. KAJIAN TEORI Pengembangan hipotesis}

1. Dampak kepemimpinan terhadap kinerja

Studi yang dilakukan (Darmawati, 2016) yang menganalisis dampak kepemimpinan dan iklim organisasi pada kinerja pegawai PT. Jasajoe Putra Mandiri membuktikan kepemimpinan dapat berpengaruh yang positif dan signifikan pada kinerja. Teori tersebut juga dapat dilihat pada studi yang dilakukan oleh (Imansyah, Arafat, \& Wardiah, 2020) yang menganalisa kepemimpinan kepala sekolah dan partisipasi komite sekolah pada kinerja guru, menghasilkan bukti bahwa kepemimpinan berpengaruh positif dan signifikan pada kinerja. Seseorang dapat menjadi pemimpin karena 
banyak hal, antara lain merupakan bakat atau bawaan sejak lahir. Artinya adaorang yang memilikibakat pemimpin dari kecil dengan menampakan sifat-sifat seorang pemimpin seperti mengajak, mengatur orang untuk melakukan sesuatu sesuai arahannya. Seseorang yang sudah ada jjiwa kepimpinan jika ada kesempatan untuk memimpinakan terlihat dengan sendirinya sifat tersebut. Memiliki bakat untuk menjadi seorang pemimpin tentunya akan memberi dampak pada kehidupan seseorang jika sudah ada didalam suatu organisasi yang membuat orang ikut dalam kepemimpinan yang bersangkutan. Selain itu seseorang juga bisa menjadi pemimpin karena memiliki sifat yang dibutuhkan sebagai seorang pemimpin. Sehingga yang bersangkutan dapat berhasil menjadi pemimpin karena memiliki sifat kepribadian baik secara fisik maupun psikologis. Untuk itu kajian ini ingin mempelajari bagaimana dampak kepemimpinan terhadap kinerja pegawai di salah satu perusahaan jasa transportasi di Kota Palembang.

2. Dampak kompensasi terhadap
kinerja
Berdasarkan penelitian terdahulu dari (Darmawati, 2014) yang menganalisis kompensasi pada prestasi kerja pegawai Fakultas Ekonomi Universitas PGRI Palembang menemukan bahwa kompensasi berpengaruh signifikan pada prestasi kerja pegawai, selain itu menurut penelitian (Ariesa, Kamal, Fransisca, Gunawan, \& Emmanuel, 2020) yang menganalisis kompensasi, pengawasan, dan disiplin kerja pada kinerja karyawan mendapatkan kesimpulan kompensasi berpengaruh positif dan signifikan pada kinerja. Salah satu tujuan pemberian kompensasi kepada pegawai adalah memberi keadilan bagi pegawai dan penghargaan apa yang sudah dilakukan bagi perusahaan. Untuk pemberian kompensasi perusahaan/organisasi dapat membuat peraturan pengaturan nilai kompensasi yang sesuai dengan ketentuan. Melalui pengaturan pemberian kompensasi akan membuat pegawai mendapatkan kompensasi sesuai dengan kinerja yang diberikan pada perusahaan. Atas dasar hal tersebut peneliti ingin mempelajari bagaimana dampak kompensasi pada kinerja pegawai disalah satu perusahaan jasa transportasi di Kota Palembang.

3. Dampak motivasi kerja terhadap kinerja

Menurut penelitian (Haryono \& Arafat, 2017) efek budaya organisasi dan motivasi kerja pada kinerja dosen di perguruan tinggi swasta membuktikanmotivasi kerja berpengaruh positif dan signifikan pada kinerja. Sedangkan menurut studi oleh (Hayati, Arafat, \& Sari, 2020) pengaruh komitmen organisasi dan komitmen kerja pada kinerja guru menghasilkan bahwa motivasi kerja dapat berpengaruh positif dan signifikan pada kinerja. Dengan demikian motivasi kerja bagi pegawai menjadi hal penting. Melalui motivasi kerja diharapkan akan timbul energi dan komitmen pegawai yang akan menimbulkan kreativitas dalam bekerja. Untuk itu studi ini dilaksanakan untuk mempelajaribagaimana dampak motivasi kerja pada kinerja pegawai disalah satu perusahaan jasa transportasi di Kota Palembang.

\section{METODE PENELITIAN}

1. Desain Penelitian dan Unit Analisis

Metode penelitian yang menggunakan penelitian kuantitatif 
melalui pengembangan intrumen penelitian, kepemimpinan, kompensasi, motivasi kerja dan kinerja pegawai pada salah satu perusahaan jasa transportasi di kota Palembang. (Sujarweni, 2015) menyatakan data primer merupakan data yang didapatlangsung melalui kuesionerberasaldari responden, atau bias juga hasil dari wawancara penelitian dari narasumber. Tentunya data yang di dapat dari data primer harus diolah kembali. Data sekunder merupakan data yangbisa diperoleh melalu ibuku, karya ilmiah, catatan, dokumentasi maupun arsip. Skala ukur menggunakan skala likert dengan jawaban skala 1-5 yang merepresentasikan dari sangat setuju sampai sangat tidak setuju.

\section{Sampel Penelitian}

Sampel yang digunakandalam penelitian ini adalah pegawai bagian SDM salah satu perusahaan penyedia jasa transportasi di Kota Palembang yang berjumlah 40 orang. Pegawai yang menjadi sampel berasal dari bagian administrasi dan operasional. Teknik penarikan sampel memakai sampel jenuh yaitu seluruh anggota populasi dijadikan sampel (Sugiyono, 2010). Perusahaan tersebut memiliki karyawan sebanyak 40 orang yang terbagi dalam unit-unit kerja.

3. Penyaringan dan Analisis Data

Penyelesaian data menggunakan aplikasi SPSS 23. Langkah-langkah yang dilaksanakan dalam pelaksanaan penelitian berupa pertama adalah dilakukan pengujian validitas dan realibiltas terlebih dahulu atas intrumen penelitian kepemimpinan, kompensasi, motivasi kerja dan kinerja. Kedua dilakukan pengujian data hasil penelitian berupa normalitas data, multikolinearitas dan heterokedastisitas. Ketiga dilakukan analisis data menggunakan uji $t$.

Tabel Pengujian Validitas Kepemimpinan

\begin{tabular}{lccc}
\hline $\begin{array}{c}\text { Item } \\
\text { Pertanyaan }\end{array}$ & $\mathbf{r}_{\text {hitung }}$ & $\begin{array}{c}\mathbf{r}_{\text {tabel }} \\
(\boldsymbol{\alpha}=\mathbf{5 \%})\end{array}$ & Hasil Validitas \\
\hline Nomor_1 & 0.740 & 0,312 & valid \\
\hline Nomor_2 & 0.386 & 0,312 & valid \\
\hline Nomor_3 & 0.494 & 0,312 & valid \\
\hline Nomor_4 & 0.416 & 0,312 & valid \\
\hline Nomor_5 & 0.787 & 0,312 & valid \\
\hline Nomor_6 & 0.425 & 0,312 & valid \\
\hline Nomor_7 & 0.425 & 0,312 & valid \\
\hline Nomor_8 & 0.520 & 0,312 & valid \\
\hline
\end{tabular}

Sumber : Data Primer yang diolah SPSS for windows ver. 23.0

Tabel Pengujian Validitas Motivasi Kerja

\begin{tabular}{lccc}
\hline $\begin{array}{c}\text { Item } \\
\text { Pertanyaan }\end{array}$ & $\mathbf{r}_{\text {hitung }}$ & $\begin{array}{c}\mathbf{r}_{\text {tabel }} \\
(\boldsymbol{\alpha}=\mathbf{5} \%)\end{array}$ & Hasil Validitas \\
\hline Nomor_1 & 0.634 & 0,312 & valid \\
\hline Nomor_2 & 0.541 & 0,312 & valid \\
\hline Nomor_3 & 0.583 & 0,312 & valid \\
\hline Nomor_4 & 0.421 & 0,312 & valid \\
\hline Nomor_5 & 0.548 & 0,312 & valid \\
\hline
\end{tabular}




\begin{tabular}{llll}
\hline Nomor_6 & 0.550 & 0,312 & valid \\
\hline Nomor_7 & 0.604 & 0,312 & valid \\
\hline Nomor_8 & 0.480 & 0,312 & valid \\
\hline Nomor_9 & 0.583 & 0,312 & valid \\
\hline Nomor_10 & 0.564 & 0,312 & valid \\
\hline Nomor_11 & 0.567 & 0,312 & valid \\
\hline Nomor_12 & 0.593 & 0,312 & valid \\
\hline Nomor_13 & 0.349 & 0,312 & valid \\
\hline Nomor_14 & 0.361 & 0,312 & valid \\
\hline Nomor_15 & 0.507 & 0,312 & valid \\
\hline Nomor_16 & 0.550 & 0,312 & valid
\end{tabular}

Sumber : Data Primer yang diolah SPSS for windows ver. 23.0

Tabel Pengujian Validitas Kompensasi

\begin{tabular}{lccc}
\hline $\begin{array}{c}\text { Item } \\
\text { Pertanyaan }\end{array}$ & $\mathbf{r}_{\text {hitung }}$ & $\begin{array}{c}\mathbf{r}_{\text {tabel }} \\
(\boldsymbol{\alpha}=\mathbf{5} \%)\end{array}$ & Hasil Validitas \\
\hline Nomor_1 & 0.634 & 0,312 & valid \\
\hline Nomor_2 & 0.546 & 0,312 & valid \\
\hline Nomor_3 & 0.628 & 0,312 & valid \\
\hline Nomor_4 & 0.397 & 0,312 & valid \\
\hline Nomor_5 & 0.395 & 0,312 & valid \\
\hline Nomor_6 & 0.597 & 0,312 & valid
\end{tabular}

Sumber : Data Primer yang diolah SPSS for windows ver. 23.0

Tabel Pengujian Validitas Kinerja

\begin{tabular}{|c|c|c|c|}
\hline $\begin{array}{c}\text { Item } \\
\text { Pertanyaan }\end{array}$ & $\mathbf{r}_{\text {hitung }}$ & $\begin{array}{c}r_{\text {tabel }} \\
(\alpha=5 \%)\end{array}$ & Hasil Validitas \\
\hline Nomor_1 & 0.507 & 0,312 & valid \\
\hline Nomor_2 & 0.512 & 0,312 & valid \\
\hline Nomor_3 & 0.448 & 0,312 & valid \\
\hline Nomor_ 4 & 0.410 & 0,312 & valid \\
\hline Nomor_5 & 0.440 & 0,312 & valid \\
\hline Nomor_6 & 0.458 & 0,312 & valid \\
\hline Nomor_ 7 & 0.512 & 0,312 & valid \\
\hline Nomor_8 & 0.487 & 0,312 & valid \\
\hline Nomor_9 & 0.422 & 0,312 & valid \\
\hline Nomor_10 & 0.428 & 0,312 & valid \\
\hline Nomor_11 & 0.475 & 0,312 & valid \\
\hline Nomor_12 & 0.352 & 0,312 & valid \\
\hline Nomor_13 & 0.375 & 0,312 & valid \\
\hline Nomor_14 & 0.432 & 0,312 & valid \\
\hline
\end{tabular}

Sumber : Data Primer yang diolah SPSS for windows ver. 23.0 
Tabel Pengujian reliabilitas

\begin{tabular}{lcc}
\hline \multicolumn{1}{c}{ Variabel } & $\begin{array}{c}\text { Nilai Cronbach } \\
\text { Alpha }\end{array}$ & Keterangan \\
\hline Kepemimpinan & 0.809 & reliabel \\
\hline Motivasi & 0.876 & reliabel \\
\hline Kompensasi & 0.784 & reliabel \\
\hline Kinerja Pegawai & 0.809 & reliabel \\
\hline
\end{tabular}

Sumber : Data Primer yang diolah SPSS for windows ver. 23.0

\section{HASIL PENELITIAN}

(Priyatno, 2018) menyatakan pengujian normalitas digunakan agar dapat mengetahui data memiliki distribusi normal atau tidak. Uji nomalitas dilakukan dengan menganalisis grafik secara normal plot atau histrogram yang mendeteksi penyebaran data (titik) di sumbu diagonal ygnampakpada grafik. Multikolinearitas menjelaskan keadaan dimana dua variabel independen atau lebih terjadinya hubungan linear sempurna atau mendekati sempurna.
Heteroskedastisitas yaitu keadaan dimana terdapat ketidaksamaan varian dari residual pada model regresi. Pengujian heterokedastisitas dapatdilakukan dengan melihat pola titik-titik pada scatterplot. Hasil pengujian dinyatakan semua data variabel penelitian baik itu kepemimpinan, kompensasi, motivasi kerja dan kinerja berdistribusi normal, tidak ada multikolinearitas antara variabel bebas dan tidak ditemukan masalah heteroskedatisitas di model regresi.

Tabel Pengujian Parsial (Uji t)

\begin{tabular}{|l|r|r|r|r|r|}
\hline Model & \multicolumn{2}{|c|}{$\begin{array}{c}\text { unstandardized } \\
\text { coefficients }\end{array}$} & $\begin{array}{c}\text { standardized } \\
\text { coefficients }\end{array}$ & \multirow{2}{*}{ Sig. } & \\
\cline { 2 - 5 } & \multicolumn{1}{c}{$\mathrm{B}$} & $\begin{array}{c}\text { Std. } \\
\text { Error }\end{array}$ & \multicolumn{1}{c|}{ Beta } & & \\
\hline (Constant) & .408 & .529 & & .772 & .445 \\
Kepemimpinan & .262 & .097 & .305 & 2.696 & .011 \\
Motivasi & .399 & .122 & .396 & 3.281 & .002 \\
Kompensasi & .230 & .090 & .325 & 2.549 & .015 \\
\hline
\end{tabular}

Sumber : Data Primer yang diolah SPSS for windows ver. 23.0

1. Kajian kepemimpinan terhadap kinerja

Berdasarkan hasil analisis diperoleh koefisien regresi kepemimpinan positif sebesar 0,262, dengan nilai signifikansi sebesar 0,011 lebih kecil dari alpha 0,05. Uji hipotesis uji t variabel Kepemimpinan diperoleh nilai thitung 2,696 $>t_{\text {tabel }} 2,028$. Dengan demikianakan terjadi Ho ditolak, Ha diterima jadi dapat dikatakan kepemimpinan berpengaruh signifikan terhadap kinerja pegawai. Hal ini sesuaidengan yang dikemukakan (Brahmasari, 2008) yang menjelaskan bahwa kepemimpinan memiliki pengaruh yang positif dan signifikan terhadap kinerja. Penelitian yang sama dilakukan oleh (Riyadi, 2011) bahwa kepemimpinan mempunyai pengaruh positif juga signifikan terhadap kinerja. Kepemimpinan merupakan faktor penting dalam mengelola suatu organisasi. Melalui kepemimpinan 
yang tepat akan mampu melakukan inovasi dan perubahan, baik dalam pelaksanaan manajemen sumber daya manusia maupun hal-hal lainnya yang mengikuti perkembangan kemajuan teknologi sehingga pemimpin diharapkan bukan hanya figur pimpinantapi sebagai tolak ukur. Sebagai pemimpin yang mengajak orang-orang dalam suatu organisasi menuju inovasi perubahan yang terus menerus haruslahseorang yang kuat dan mampu bertahan menghadapi tantangan dan perubahan yang dating dengan tiba-tiba. Pemimpin harus mampu mencari jalan keluar dari setiap permasalahan yangdatangdaridalamataudariluarperus ahaan, selain itu pemimpin dapat memanfaatkan secara maksimal sumber daya dalam organisasi sehingga dapat mencapai tujuan yang diinginkan. Seseorang dapat menjadi pemimpin yang berhasil jika mampu menggerakkan, mendorong, mengajak, memanfaatkan sumber daya yang dimiliki organisasi secara baikdan tentunya akan selalu tercipta situasi dan kondisi lingkungan kerja yang aman, nyaman dan menyenangkan bagi seluruh pegawai dalam mencapai tujuan organisasi.

\section{Kajian kompensasi terhadap kinerja}

Berdasarkan hasil studi diperoleh koefisien regresi kompensasipositif sebesar 0,230, dengan nilai signifikansi sebesar 0,015lebih kecil dari alpha 0,05. Uji hipotesis uji $t$ variabel Kompensasi diperoleh nilai $t_{\text {hitung }} 2,549>t_{\text {tabel }} 2,028$ artinya, kompensasi secara parsial berpengaruh positif secara signifikan pada kinerja pegawai. Hasil studi ini sesuai yang disampaikan (Riyadi, 2011) kompensasi secara parsial berpengaruh positif secara signifikan pada kinerja. Hasil ini mendukung studi
(Ariesa, Kamal, Fransisca, Gunawan, \& Emmanuel, 2020) yang menyatakan secara parsial kompensasi berpengaruh positif signifikan pada kinerja. kompensasi merupakan faktor penting bagi pegawai. Kompensasi yang diberikan oleh organisasi kepada pegawai membuat efek yang positif dalam peningkatan kinerja pegawai. Kompensasi yang tepat, sesuai dan adil dapat memberikan pengaruh positif pada peningkatan kinerja. Dengan pemberian kompensasi yang baik juga dapat menciptakan nilai kepuasan karyawan yang berakibat tingginya kinerja pegawai tersebut. Oleh karena itu apabila pihak manajemen perusahaan ingin meningkatkan kinerja pegawai tentunya harus memperhatikan kompensasi yang diberikan kepada pegawai dengan mempertimbangkan hal-hal seperti, kompetensi, masa kerja, pendidikan, beban kerja dan lainnya.

3. Kajian motivasi kerja terhadap kinerja

Berdasarkan hasil studi diperoleh koefisien regresi motivasi kerja positif sebesar 0,399, dengan nilai signifikansi sebesar 0,002 lebih kecil dari alpha 0,05. Uji hipotesis uji $t$ variabel motivasi kerja diperoleh nilai $t_{\text {hitung }} 3,281>t_{\text {tabel }} 2,028$ artinya motivasi kerjasecara parsial akanberpengaruh positif signifikan pada kinerja pegawai. Hasil studi ini mendukung studi yang sudahdilakukan oleh (Haryono \& Arafat, 2017)membuktikan bahwa secara parsial motivasi kerjadapatberpengaruh positif dan signifikan pada kinerja pegawai.Studi yang dilakukan oleh (Brahmasari, 2008) juga menghasilkan secara parsial motivasi kerja berpengaruh positif signifikan pada kinerja. Motivasi seseorang dapat muncul dari dalam 
dirinya sendiri atau karena dorongan dari luar. Motivasi dari dalam bisa timbul karena adanya kebutuhan, keinginan dalam dirinya untuk memiliki sesuatu atau mencapai sesuatu. Kemudian motivasi juga bisa timbul karena dorongan dari luar, sehingga apabila harapan sudah terpenuhi biasanya dorongan dari dalam diri akan menurun dan melemah dengan sendirinya, setelah itu dibutuhkan hal baru yang menjadi acuan baru untuk menimbulkan motivasi seseorang. Oleh karena itu, pada dasarnya kebutuhan, keinginan manusia untuk memiliki sesuatu atau mencapai sesuatu akan menjadi dorongan kuat yang memotivasi dirinya untuk mewujudkannya. Orang yang tinggi motivasi kerjanya biasanya akan memiliki kinerja yang tinggi, begitu juga sebaliknya. Untuk itu jika perusahaan ingin meningkatkan kinerja pegawainya, maka motivasi kerja pegawai harus ditingkatkan. Peningkatkan motivasi kerja dapat dilakukan dengan cara antara lain pemenuhan hak-hak pegawai dalam bekerja, pemenuhan kebutuhan sarana dan prasarana dalam bekerja, keadaan disekitar lingkungan kerja yang aman, tentram, dan terpelihara. Suasana hati pegawai sangat mempengaruhi dalam pelaksanaan kegiatan yang akan dilakukannya.Untuk itu selain dalam diri pegawai sendiri membangun batin yang nyaman juga kedaaan dilingkungan kerja yang selalu menciptakan semangat untuk bekerja secara maksimal.

\section{E. KESIMPULAN DAN SARAN}

Dari hasil studi dan analisis maka bisa disimpulkan hal-hal sebagai berikut:

1) Secara parsial kepemimpinan berpengaruh positif juga signifikan pada kinerja pegawai, berdasarkan hal tersebut pimpinan perusahaan sebaiknya dapat menjalankan manajemen kepemimpinan yang baik, selaras dengan visi misi perusahaan sehingga bisa diterima dan membuat rasa nyaman bekerja bagi pegawai.Sikap kepemimpinan yang baikakan mempengaruhi orang bertindak yang sama, karena pemimpin merupakan cermin untuk pegawai bersikap dan bertindak.

2) Motivasi berpengaruh positif dan signifikan terhadap kinerja pegawai, maka diharapkan kepada pimpinan perusahaan dapat memberikan motivasi kerja yang berkesinambungan melalui rapat dan pertemuan yang dihadiri para pegawai agar pegawai mampu bekerja sama dengan pimpinan dan sesama rekan kerja secara baik sehingga tugas dan tanggung jawab yang di bebankan pada pegawai bisa dituntaskan dengan waktu yang sesuai ketentuan.

3) Kompensasi berpengaruh positif dan signifikan terhadap kinerja pegawai, berdasarkan hal tersebut diharapkan pimpinan menjadikan kompensasi juga hal terpenting dalam peningkatan kinerja pegawai. Kompensasi yang sesuai dengan prestasi kerja yang diberikan perusahaan akan membuat pegawai termotivasi bekerja lebih giat, berprestasi, yang akan menguntungkan bagi organisasi. Selain itu kompensasi yang berjalan dengan baik dapat mempertahankan juga menjaga keberadaan sumber daya manusia yang dimiliki perusahaan atau organisasi tersebut.

4) Selain itu agar kinerja pegawai dapat maksimal maka perlu 
diadakan upaya-upaya dalam peningkatan kinerja pegawai seperti penilaian kinerja yang jujur sesuai yang terjadi dalam keseharian karena dengan penilaian yang jujurakan berpengaruh pada pegawai untuk melakukan pekerjaan lebih baik setiap harinya, pemberian kesejahteraan, kenyamanan dalam melaksanakan pekerjaan, penghargaan atas prestasi kerja, dan lain-lain.

\section{DAFTAR PUSTAKA}

Ardana, K., Mujiati, W., \& Utama, M. (2012). Manajemen Sumber Daya Manusia. Yogyakarta: Graha IImu.

Ariesa, Y., Kamal, J., Fransisca, Gunawan, \& Emmanuel, A. (2020). Pengaruh kompensasi, pengawasan, dan disiplin kerja terhadap kinerja karyawan. JMKSP (jurnal manajemen, kepemimpinan, dan supevisi pendidikan), Hal. 92-99, Volume 5 , nomor 2.

Brahmasari, I. A. (2008). Pengaruh Motivasi Kerja, Kepemimpinan dan Budaya Organisasi Terhadap Kepuasan Kerja Karyawan dan Dampaknya pada Kinerja Perusahaan (studi kasus pada PT. Pei Hai International Wiratama Indonesia). Jurnal Manajemen dan Kewirausahaan Vol.10 No.2, 124-135.

Darmawati, T. (2014). Pengaruh Kompensasi terhadap Prestasi Kerja Pegawai pada Fakultas Ekonomi Universitas PGRI Palembang. Media Wahana
Ekonomika, 58-69 Volume 10 nomor 4.

Darmawati, T. (2016). Pengaruh Kepemimpinan dan Iklim Organisasi terhadap Kinerja pegawai PT. Jasajoe Putra Mandiri . Media Wahana Ekonomika, 59-70 Volume 12 nomor 4.

Haryono, S., \& Arafat, Y. (2017). Effects of organizational culture and work motivation on Job performance among the private university. Information (Japan), Pp 5563-5575, Volume 20, Number $8(A)$.

Hasibuan, M. (2014). Manajemen Sumber Daya Manusia. Jakarta: Bumi Aksara.

Hayati, R., Arafat, Y., \& Sari, A. P. (2020). Pengaruh Komitmen Organisasi dan Komitmen Kerja terhadap Kinerja Guru. JMKSP (jurnal manajemen, kepemimpinan, dan supervisi pendidikan), Hal. 100-111, Volume 5, nomor 2.

Imansyah, M., Arafat, Y., \& Wardiah, D. (2020). Pengaruh Kepemimpinan Kepala Sekolah dan partisipasi komite sekolah terhadap kinerja guru. JMKSP (jurnal manajemen, kepemimpinan, dan supervisi pendidikan), Hal. 135-143, Volume 5 nomor 2.

Moeheriono. (2012). Pengukuran Kerja Berbasis Kompetensi. Depok: PT. Grafindo Persada.

Priyatno, D. (2018). Panduan mudah olah data bagi mahasiswa \& umum. Yogyakarta: ANDI. 
Riyadi, S. (2011). Pengaruh Kompensasi Finansial, Gaya Kepemimpinan, dan Motivasi Kerja Terhadap Kinerja Karyawan pada Perusahaan Manufaktur di Jawa Timur. Manajemen dan Kewirausahaan, hal. 40-45, Volume 13 Nomor 1.

Sastrohadiwiryo, S. (2013). Pengantar Manajemen. Jakarta: Bumi Akasara.

Sugiyono. (2010). Metode Penelitian Bisnis. Bandung: Alfabeta.

Sujarweni, W. (2015). Metode Penelitian Bisnis \& Ekonomi. Yogyakarta: Pustaka Baru Press.

Sunyoto, D. (2012). Teori, Kuisioner dan Analisis Data Sumber Daya Manusia. Yogyakarta: CAPS.
Suparyadi. (2015). Manajemen Sumber Daya Manusia, Menciptakan

Bersaing Berbasis Kompetisi SDM. Jakarta: Andi.

Suranta, S. (2002). Dampak motivasi karyawan pada hubungan antara gaya kepemimpinan dengan kinerja karyawan perusahaan bisnis. Jurnal Empirika, Volume 15 nomor 2, 116-138.

Wibowo. (2014). Manajemen Kinerja. Depok: PT. Raja Grafindo Persada.

Wukir. (2013). Manajemen Kinerja. Depok: PT. Raja Grafindo. 